\title{
Government Debt and Optimal Monetary and Fiscal Policy*
}

\author{
Klaus Adam \\ Mannheim University and CEPR
}

September 30, 2010

\begin{abstract}
How do different levels of government debt affect the optimal conduct of monetary and fiscal policies? And what do these optimal policies imply for the evolution of government debt over time? To provide an answer, this paper studies a standard monetary policy model with nominal rigidities and monopolistic competition and adds to it a fiscal authority that issues nominal non-state contingent debt, levies distortionary labor income taxes and determines the level of public goods provision. Higher government debt levels make it optimal to reduce public spending, so as to dampen the adverse incentive effects of distortionary taxes, but also strongly influence the optimal stabilization response following technology shocks. In particular, higher debt levels give rise to larger risks to the fiscal budget and to tax rates. This makes it optimal to reduce government debt over time. The optimal speed of debt reduction is missed when using first order approximations to optimal policies, but is shown to be quantitatively significant in a second order approximation, especially when technology movements are largely unpredictable in nature.
\end{abstract}

Keyword: Ramsey optimal policy, second-order approximation, noncontingent debt, sticky prices

JEL Class No: E63, E61

\section{Introduction}

Following the recent financial crisis and the ensuing 'Great Recession', governments in many OECD economies have implemented expansionary fiscal policy measures in addition to offering rescue packages of unprecedented size to the financial sector. These decisions have lead to a considerable increase

\footnotetext{
${ }^{*}$ Thanks go to Eric Leeper and Alex Wolman, as well as to Viktor Winschel, an anonymous referee, and seminar participants at the European University Institute, Köln University, and the EER Philadelphia Conference 2010. All errors remain mine.
} 
in the level of government indebtedness, triggering for some countries even fears about the sustainability of public finances. Figure 1 illustrates this fact by depicting the evolution of the central governments' liabilities in relation to GDP for a selected group of OECD economies. Debt levels strongly increased over the period 2007-2009 and the OECD forecasts for the years 2010 and 2011 show that debt levels are expected to increase even further.

These developments raise the important question which normative implications follow from the large build-up of government debt for the conduct of monetary and fiscal policy in the future? Should stabilization attempts in the future depend on the fact that government debt is higher now? Is it optimal to keep government debt at these elevated levels or should it be reduced over time? To provide an answer, the present paper analyzes a stylized dynamic equilibrium model and determines how the optimal conduct of monetary and fiscal policy depends on the level of accumulated government debt and how debt evolves under such optimal policies.

The paper considers three government instruments that are generally considered relevant for the conduct of stabilization policy, namely (1) monetary policy defined as control of the short-term nominal interest rate, (2) fiscal policy in the form of spending decisions on public goods, and (3) a fiscal financing decision determining whether to use labor income taxes or government debt as means to finance current expenditure, where government debt is assumed to be nominal and non-state contingent. ${ }^{1}$ The paper determines how these tools should be used as stabilization instruments in response to technology shocks and how this should depend on the level of outstanding government debt. In addition, it determines how the government debt level evolves under optimal monetary and fiscal policies.

The economic environment considered in this paper features three important distortions. First, firms are assumed to possess monopoly power in product markets which allows them to charge a mark-up over marginal cost. This causes output to generally fall short of its first best level. Second, fiscal policy has to use distortionary labor income taxes to finance public goods provision and interest payments on outstanding government debt. Public spending and government debt thus have additional adverse labor supply and output effects. Finally, nominal rigidities in the price of final goods prevent prices from fully adjusting in response to economic disturbances and policy measures. ${ }^{2}$

Each of these distortions has important implications for the optimal conduct of policy. Firms' monopoly power and the fact that the government can levy only distortionary income taxes make it optimal to reduce government

\footnotetext{
${ }^{1}$ Much of the public finance literature treats the government spending process as exogenous, which is hard to understand from a normative perspective. Exceptions are Adam and Billi (2008), Leith and Wren-Lewis (2007), or Leith et al. (2009).

${ }^{2}$ Nominal rigidities, however, also allow monetary policy to affect real interest rates and thereby the real allocations in the economy.
} 


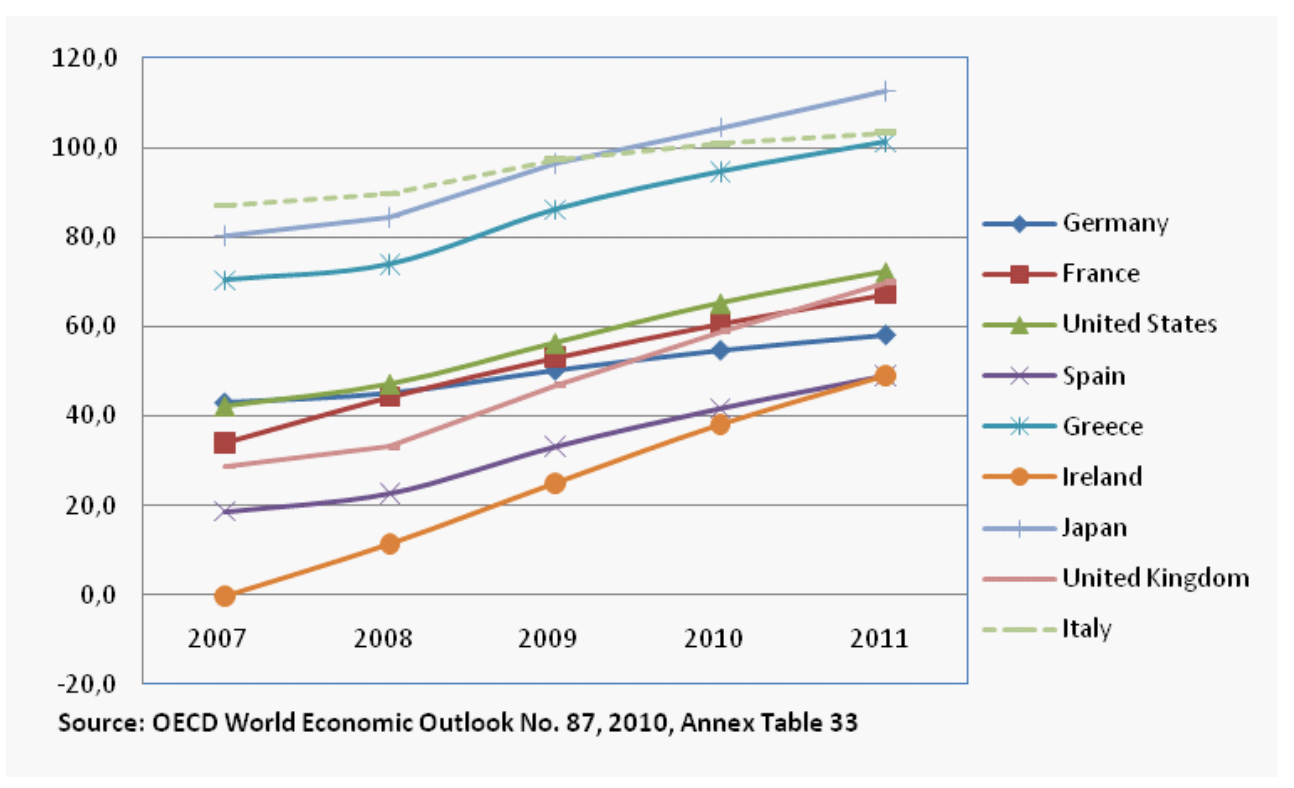

Figure 1: Central Government Debt/GDP: History \& OECD Forecast

spending below what is suggested by the first-best allocation rule for public and private consumption. It is thereby optimal to reduce public goods provision more, the higher is the outstanding government debt/GDP ratio.

Furthermore, as in Schmitt-Grohé and Uribe (2004), nominal rigidities prevent the government from using price level changes as an important source of state-contingent taxation in the presence of nominal government debt. As a result, government debt optimally follows a near random walk, as in Barro (1979) and Aiyagari et al. (2002). However, unlike in these latter papers, the standard deviations of the innovation to this near random walk crucially depends on the level of outstanding government debt. This result emerges because the present paper considers a model in which technology shocks are the underlying driving force. Such shocks give rise to variations in the tax base and these have larger fiscal budget implications the larger is the labor tax rate, i.e., the higher is the outstanding amount of government debt. $^{3}$

The fact that larger government debt gives rise to larger risks to the fiscal budget and to the tax rate has important implications for optimal debt dynamics. In particular, it provides incentives to reduce government debt over time so as to reduce budget risk (provided the initial debt level is positive). As a result, debt dynamics deviate from random walk behavior in

\footnotetext{
${ }^{3}$ In Barro (1979) and Aiyagari et al. (2002) government spending is assumed exogenous and spending shocks are the only source of randomness, so that fiscal budget risks are largely independent from the government debt level.
} 
a second order approximation to optimal policy. The quantitative strength of this force can be significant, e.g., it can be optimal to reduce the debt/GDP ratio by about $0.6 \%$ each year, but this depends on whether or not the variance of technology shocks is largely due to predictable or unpredictable movements. Unpredictable components thereby provide stronger incentives for debt reduction.

In the present setting, which considers homothetic preferences over public and private consumption, debt optimally increases if its initial level is negative and optimally decreases if the initial level is positive. When initial government debt is zero, this turns out to be an absorbing state (to second order accuracy). Specifically, without outstanding debt, it is optimal to balance any revenue shortfall from an adverse technology shock exclusively through a corresponding reduction in government spending. Tax rates and debt then remain unchanged in response to shocks. This suggests that debt optimally reverts to zero over time.

The economic model in this paper is related to earlier work by Adam and Billi $(2008,2009)$. It extends these earlier settings by allowing for distortionary income taxation and for government debt dynamics at the same time. Moreover, it considers fully optimal stabilization policies while previous work was concerned with time-consistent (or discretionary) policymaking and the design of institutions that would allow overcoming the distortions generated by the lack of commitment.

The paper is organized as follows. Section 2 describes the economic model and derives the implementability conditions summarizing optimal private sector behavior. After determining the first best allocation in section 3 , section 4 describes the optimal policy problem and the numerical solution strategy. It also derives analytical results regarding the deterministic steady state outcomes associated with optimal monetary and fiscal policy. The quantitative implication of government debt for the steady state outcomes is analyzed in section 5, while section 6 determines the impulse responses of the economy to technology shocks and shows how these depend on the outstanding level of government debt. Section 7 discusses the implications for the optimal drift of government debt over time and shows that the quantitative implications arising from budget risk considerations can be sizable. Section 8 discusses how results change if government spending cannot adjust in response to technology shocks. A conclusion summarizes.

\section{Description of the Economic Model}

The next sections adapt the sticky price model presented in Adam and Billi (2008) to the empirically more relevant setting with distortionary income taxes and credible government debt. Besides presenting the model ingredients, this section derives the implementability constraints characterizing 
optimal private sector behavior, i.e., derives the optimality conditions determining households' consumption and labor supply decisions and firms' price setting decisions.

\subsection{Private Sector}

There is a continuum of identical households with preferences given by

$$
E_{0}\left[\sum_{t=0}^{\infty} \beta^{t} u\left(c_{t}, h_{t}, g_{t}\right)\right]
$$

where $c_{t}$ denotes consumption of an aggregate consumption good, $h_{t} \in[0,1]$ denotes the labor supply, and $g_{t}$ public goods provision by the government in the form of aggregate consumption goods. Throughout the paper we impose the following conditions:

Condition $1 u(c, h, g)$ is separable in $c, h$, and $g$, and $u_{c}>0, u_{c c}<0$, $u_{h}<0, u_{h h} \leq 0, u_{g}>0, u_{g g}<0$.

Each household produces a differentiated intermediate good. Demand for that good is given by

$$
y_{t} d\left(\frac{\widetilde{P}_{t}}{P_{t}}\right)
$$

where $y_{t}$ denotes (private and public) demand for the aggregate good, $\widetilde{P}_{t}$ is the price of the good produced by the household, and $P_{t}$ is the price of the aggregate good. The demand function $d(\cdot)$ satisfies

$$
\begin{aligned}
d(1) & =1 \\
\frac{\partial d}{\partial\left(\widetilde{P}_{t} / P_{t}\right)}(1) & =\eta
\end{aligned}
$$

where $\eta \in(-\infty,-1)$ is the price elasticity of demand for the differentiated goods. Importantly, the previously stated assumptions about the demand function are consistent with optimizing individual behavior when private and public consumption goods are Dixit-Stiglitz aggregates of the goods produced by different households, see Adam and Billi (2008) for details.

The household chooses $\widetilde{P}_{t}$ and then hires the necessary amount of labor $\widetilde{h}_{t}$ to satisfy the resulting product demand, i.e.,

$$
z_{t} \widetilde{h_{t}}=y_{t} d\left(\frac{\widetilde{P_{t}}}{P_{t}}\right)
$$

where $z_{t}$ is an aggregate technology shock which evolves according to

$$
z_{t+1}=\left(1-\rho_{z}\right)+\rho_{z} z_{t}+\varepsilon_{z, t+1}
$$


with

$$
\varepsilon_{z, t+1} \sim i i N\left(0, \sigma^{2}\right)
$$

Following Rotemberg (1982) we introduce sluggish nominal price adjustment by assuming that firms face quadratic resource costs for adjusting prices according to

$$
\frac{\theta}{2}\left(\frac{\widetilde{P}_{t}}{\widetilde{P}_{t-1}}-1\right)^{2}
$$

where $\theta>0$. The flow budget constraint of the household is then given by

$P_{t} c_{t}+B_{t}=R_{t-1} B_{t-1}+P_{t}\left[\frac{\widetilde{P}_{t}}{P_{t}} y_{t} d\left(\frac{\widetilde{P}_{t}}{P_{t}}\right)-w_{t} \widetilde{h}_{t}-\frac{\theta}{2}\left(\frac{\widetilde{P}_{t}}{\widetilde{P}_{t-1}}-1\right)^{2}\right]+P_{t} w_{t} h_{t}\left(1-\tau_{t}\right)$

where $B_{t}$ denotes nominal government bonds that pay $B_{t} R_{t}$ in period $t+1$, $w_{t}$ is the real wage paid in a competitive labor market, and $\tau_{t}$ is a labor income tax. ${ }^{4}$

Although nominal government bonds are the only available financial instrument, adding complete financial markets for claims between households would make no difference for the analysis: since households have identical incomes in a symmetric price setting equilibrium, there exists no incentive to actually trade such claims. One should note that we also abstract from money holdings. This should be interpreted as the 'cashless limit' of an economy with money, see Woodford (1998). Money thus imposes only a lower bound on the gross nominal interest rate, i.e.,

$$
R_{t} \geq 1
$$

each period. Abstracting from money entails that we ignore seigniorage revenues generated in the presence of positive nominal interest rates. Given the size of these revenues in relation to GDP in industrialized economies, this does not seem to be an important omission for the analysis conducted here. ${ }^{5}$

Finally, we impose a no Ponzi scheme constraint on household behavior, i.e.,

$$
\lim _{j \rightarrow \infty} E_{t}\left[\left(\prod_{i=0}^{t+j-1} \frac{1}{R_{i}}\right) B_{t+j}\right] \geq 0
$$

The household's problem consists of choosing state-contingent processes $\left\{c_{t}, h_{t}, \widetilde{h}_{t}, \widetilde{P}_{t}, B_{t}\right\}_{t=0}^{\infty}$ so as to maximize (1) subject to (2), (3), and (5) taking as given $\left\{y_{t}, P_{t}, w_{t}, R_{t}, g_{t}, \tau_{t}\right\}_{t=0}^{\infty}$ as well as the exogenous stochastic productivity process $\left\{z_{t}\right\}_{t=0}^{\infty}$.

\footnotetext{
${ }^{4}$ Considering instead income or consumption taxes is equivalent to a labor income tax plus a lump sum tax (on profits).

${ }^{5}$ As emphasized by Leeper (1991), however, seigniorage may nevertheless be an important marginal source of revenue.
} 
Using equation (2) to substitute $\widetilde{h}_{t}$ in (3) and letting the Lagrange multiplier on (3) be given by $\beta^{t} \lambda_{t} / P_{t}$, the first order conditions of the household's problem are then equations (2), (3), and (5) holding with equality and also

$$
\begin{gathered}
u_{c, t}=\lambda_{t} \\
u_{h, t}=-\lambda_{t} w_{t}\left(1-\tau_{t}\right) \\
\lambda_{t}=\beta E_{t}\left[\lambda_{t+1} \frac{R_{t}}{\Pi_{t+1}}\right] \\
0=\lambda_{t}\left(y_{t} d\left(r_{t}\right)+r_{t} y_{t} d^{\prime}\left(r_{t}\right)-\frac{w_{t}}{z_{t}} y_{t} d^{\prime}\left(r_{t}\right)-\theta\left(\Pi_{t} \frac{r_{t}}{r_{t-1}}-1\right) \frac{\Pi_{t}}{r_{t-1}}\right) \\
+\beta \theta E_{t}\left[\lambda_{t+1}\left(\frac{r_{t+1}}{r_{t}} \Pi_{t+1}-1\right) \frac{r_{t+1}}{r_{t}^{2}} \Pi_{t+1}\right]
\end{gathered}
$$

where

$$
r_{t}=\frac{\widetilde{P}_{t}}{P_{t}}
$$

denotes the relative price. Furthermore, there is the transversality constraint

$$
\lim _{j \rightarrow \infty} E_{t}\left(\beta^{t+j} u_{c, t+j} \frac{B_{t+j}}{P_{t+j}}\right)=0
$$

which has to hold at each contingency.

\subsection{Government}

The government consists of two authorities. First, there is a monetary authority which controls the nominal interest rates on short-term nominal bonds through open market operations. Since we consider a cashless limit economy, the open market operations are infinitesimally small allowing us to abstract from seigniorage revenue. Second, there is a fiscal authority deciding on the level of government expenditures, labor income taxes and on debt policy. Government expenditures consist of spending for the provision of public goods $g_{t}$ and for interest payments on outstanding debt. The level of public goods provision is a choice variable of the government. The government finances current expenditures by raising labor income taxes and by issuing new debt so that its budget constraint is given by

$$
\frac{B_{t}}{P_{t}}+\tau_{t} w_{t} h_{t}=g_{t}+\frac{R_{t-1}}{\Pi_{t}} \frac{B_{t-1}}{P_{t-1}}
$$

The government can credibly commit to repay its debt and government debt is assumed to be nominal and not state-contingent, consistent with the type of debt typically issued by governments around the globe. These features 
imply, however, that monetary policy decisions affect the government budget through two channels: first, the nominal interest rate policy of monetary authority influences directly the nominal return the government has to offer on its instruments; second, nominal interest rate decisions also affect the price level and thereby the real value of outstanding government debt. Thus, to the extent that the monetary policy can affect the real interest rate or the price level, it will affect the government budget, as is the case in DiazGimenez et al. (2008). In what follows we assume that government debt and tax policies are such that the no-Ponzi constraint (5) and the transversality constraint (10) are both satisfied.

\subsection{Rational Expectations Equilibrium}

In a symmetric equilibrium the relative price is given by $r_{t}=1$ for all $t$. The private sectors' optimality conditions can then be condensed into a (non-linear) Phillips curve

$$
\begin{aligned}
u_{c, t}\left(\Pi_{t}-1\right) \Pi_{t} & =\frac{u_{c, t} z_{t}}{\theta} h_{t}\left(1+\eta+\frac{u_{h, t}}{u_{c, t}\left(1-\tau_{t}\right)} \frac{\eta}{z_{t}}\right) \\
& +\beta E_{t}\left[u_{c, t+1}\left(\Pi_{t+1}-1\right) \Pi_{t+1}\right]
\end{aligned}
$$

and a consumption Euler equation

$$
u_{c, t}=\beta E_{t}\left[u_{c, t+1} \frac{R_{t}}{\Pi_{t+1}}\right]
$$

Using (6) and (7) and defining

$$
b_{t}=\frac{B_{t}}{P_{t}}
$$

the government budget constraint can be expressed as

$$
b_{t}-\frac{\tau_{t}}{1-\tau_{t}} \frac{u_{h, t}}{u_{c, t}} h_{t}=g_{t}+\frac{R_{t-1}}{\Pi_{t}} b_{t-1}
$$

Definition 1 (Rational Expectations Equilibrium) Given the initial outstanding debt level $\left(R_{-1} b_{-1}\right)$, a Rational Expectations Equilibrium (REE) consists of a sequence of government policies $\left\{R_{t} \geq 1, \tau_{t}, g_{t}, b_{t}\right\}_{t=0}^{\infty}$ and private sector choices $\left\{c_{t}, h_{t}, \Pi_{t}\right\}_{t=0}^{\infty}$ satisfying equations (12) and (13), the market clearing condition

$$
c_{t}+\frac{\theta}{2}\left(\Pi_{t}-1\right)^{2}+g_{t}=z_{t} h_{t},
$$

the government budget constraint (14), the no-Ponzi constraint (5), and the transversality condition (10). 


\section{First Best Allocation}

The first best allocation, which takes into account only household preferences and the constraints imposed by the production technology, satisfies

$$
u_{g, t}=u_{c, t}=-\frac{u_{h, t}}{z_{t}}
$$

which shows that it is optimal to equate the marginal utilities of private and public consumption to the marginal disutility of work where the latter is scaled by labor productivity. This simple allocation rule is optimal because it is equally costly to produce the public and the private consumption goods.

\section{Optimal Monetary and Fiscal Policy}

This section describes the monetary and fiscal policy problem. It is important to note that - due to the existence of a number of important economic distortions - policy can generally not achieve the first best allocation determined in the previous section. First, market power by firms generally implies that wages fall short of their marginal product, so that labor supply and therefore output is too low relative to the optimal allocation. ${ }^{6}$ Second, the requirement to finance government expenditure and interest payments on outstanding government debt with distortionary income taxes additionally depresses labor supply and output. Third, the presence of nominal rigidities may prevent the price system from providing the appropriate scarcity signals. Monetary and fiscal policy will seek to minimize the effects of all these distortions. As we will see below, this will involve reducing government consumption below its first best level so as to reduce the averse labor supply consequences of income taxes.

The optimal policy problem (Ramsey problem) which takes into account the existence of all these distortion is given by

$$
\begin{aligned}
\max _{\left\{c_{t}, h_{t}, \Pi_{t}, R_{t} \geq 1, \tau_{t}, g_{t}, B_{t} / P_{t}\right\}_{t=0}^{\infty}} & E_{0}\left[\sum_{t=0}^{\infty} \beta^{t} u\left(c_{t}, h_{t}, g_{t}\right)\right] \\
\text { s.t.: } & \text { Equations }(12),(13),(14),(15) \text { for all } t \\
& R_{-1} b_{-1} \text { given }
\end{aligned}
$$

\footnotetext{
${ }^{6}$ This assumes non-negative income tax rates, as are required when government debt is non-negative.
} 
The Lagrangian of the problem is

$$
\begin{aligned}
& \max _{\left\{c_{t}, h_{t}, \Pi_{t}, R_{t} \geq 1, \tau_{t}, g_{t}, b_{t}\right\}_{t=0}^{\infty}} \min _{\left\{\gamma_{t}^{1}, \gamma_{t}^{2}, \gamma_{t}^{3}, \gamma_{t}^{4}\right\}_{t=0}^{\infty}}\left[\begin{array}{l}
\sum_{t=0}^{\infty} \beta^{t} u\left(c_{t}, h_{t}, g_{t}\right) \\
+\beta^{t} \gamma_{t}^{1}\left(\begin{array}{c}
u_{c, t}\left(\Pi_{t}-1\right) \Pi_{t}-\frac{u_{c, t} z_{t}}{\theta} h_{t}\left(1+\eta+\frac{u_{h, t}}{u_{c, t}\left(1-\tau_{t}\right)} \frac{\eta}{z_{t}}\right) \\
E_{0}
\end{array}\right) \\
+\beta^{t} \gamma_{t}^{2}\left(\frac{u_{c, t}}{R_{t}}-\beta \frac{u_{c, t+1}}{\Pi_{t+1}}\right) \\
+\beta^{t} \gamma_{t}^{3}\left(z_{t} h_{t}-c_{t}-\frac{\theta}{2}\left(\Pi_{t+1}-1\right) \Pi_{t+1}^{2}-g_{t}\right) \\
+\beta^{t} \gamma_{t}^{4}\left(b_{t}-\frac{\tau_{t}}{1-\tau_{t}} \frac{u_{h, t}}{u_{c, t}} h_{t}-g_{t}-\frac{R_{t-1}}{\Pi_{t}} b_{t-1}\right)
\end{array}\right]
\end{aligned}
$$

The first order necessary conditions for the Lagrangian problem are derived in appendix A.1. The appendix shows that the nonlinear solution to these FOCs take the form

$$
y_{t}=g\left(x_{t}, \sigma\right)
$$

where $y_{t}=\left(c_{t}, h_{t}, \Pi_{t}, R_{t}, \tau_{t}, g_{t}, \gamma_{t}^{1}, \gamma_{t}^{2}, \gamma_{t}^{3}, \gamma_{t}^{4}\right)$ denote the decision variables and $x_{t}=\left(z_{t}, \mu_{t}^{1}, \mu_{t}^{2}, b_{t-1}, R_{t-1}\right)$ the state variables. The parameter $\sigma$ in the function (18) indicates that the solution depends on the standard deviation of the technology shocks $\sigma$. The state variables $x_{t}$ evolve according to

$$
\begin{aligned}
z_{t+1} & =\mu_{z}+\rho_{z} z_{t}+\alpha_{z, 0} \varepsilon_{z, t+1} \\
\mu_{t+1}^{1} & =\gamma_{t}^{1} \\
\mu_{t+1}^{2} & =\gamma_{t}^{2} \\
b_{t} & =\frac{\tau_{t}}{1-\tau_{t}} \frac{u_{h, t}}{u_{c, t}} h_{t}+g_{t}+\frac{R_{t-1}}{\Pi_{t}} b_{t-1} \\
R_{t} & =R_{t}
\end{aligned}
$$

The states $\mu_{t}^{i}(i=1,2)$ denote the lagged Lagrange multipliers associated with the forward-looking constraints in (17). At time zero, these states assume initial values $\mu_{0}^{i}=0(i=1,2)$. As is well known, this gives rise to transitory non-stationary components in the solution to the optimal policy problem, even in the absence of shocks. Specifically, in the initial period the policymaker may find it optimal to generate 'surprise' inflation so as to erode the real value of any outstanding government debt. Likewise, the policymaker may find it optimal to transitorily increase taxes. In what follows, I abstract from these non-stationary deterministic components of optimal policy and focus instead on the time-invariant deterministic long-run outcome. This outcome will be called the Ramsey steady state. Technically, time-invariance can be achieved by setting the time zero values of $\mu_{0}^{i}$ $(i=1,2)$ equal to their steady state value rather than to zero. Economically, this amounts to imposing an initial commitment on the policymaker not to generate 'surprise' movements in taxes, government spending, or nominal interest rates in period zero. This is standard practice in the optimal taxation 
literature, e.g., Chari et al. (1991). Implicitly, I also impose the constraint that the policymaker at time $t=0$ is required to repay the outstanding debt $R_{-1} b_{-1}$. As will be shown below, this constraint is binding; without this constraint it would be optimal to default on the inherited debt level at time $t=0$.

\subsection{Deterministic Steady State: Analytical Results}

The model possesses a continuum of deterministic Ramsey steady states, each of which is associated with a different level of government debt. ${ }^{7}$ To see this note that the first order condition with respect to bonds from the optimal policy problem (17) is given by

$$
0=\gamma_{t}^{4}-\beta E_{t} \gamma_{t+1}^{4} \frac{R_{t}}{\Pi_{t+1}}
$$

In a deterministic steady state, the Euler equation (13) implies

$$
\frac{R}{\Pi}=\beta^{-1}
$$

so that the first order condition for bonds stated above imposes no restrictions on the deterministic steady state outcomes: there exists an indeterminacy of dimension one.

Despite the existence of a continuum of deterministic steady states, these steady states share a number of common properties. As shown in appendix A.3 all deterministic Ramsey steady states satisfy

$$
\begin{aligned}
& \Pi=1 \\
& R=\beta^{-1}
\end{aligned}
$$

Equation (24) shows that it is optimal to implement price stability in the absence of shocks. This holds independently of the level of outstanding government debt and shows that it is suboptimal to use inflation in steady state with the objective to reduce the real value of outstanding government debt. Equation (25) gives the nominal interest rate consistent with price stability. From $\beta<1$ it follows that nominal interest rates are positive.

Using the steady state real interest rate derived above, the steady state government budget constraint can be written as

$$
\tau_{t} w_{t} h_{t}=g_{t}+\widetilde{x}
$$

with $\widetilde{x}$ given by

$$
\widetilde{x}=\left(\beta^{-1}-1\right) b
$$

\footnotetext{
${ }^{7}$ The different deterministic steady states also imply different values for the initial state variables $\mu_{0}^{i}$, as explained in the previous sections. This is the case because the incentives to generate 'surprise' movements in policy vary with the initial debt level.
} 
and denoting the interest rate payments on outstanding government debt. From an economic point of view, interest payments involve just income redistribution, but in an environment with distortionary taxation such redistribution is costly to provide and has real consequences. It is through this channel that government debt affects the optimal allocations.

Appendix A.3 shows that is optimal to set

$$
-u_{h} \leq u_{g}
$$

with a strict inequality if government debt is positive (or at least not too negative). Equation (27) demonstrates that it is optimal to reduce public spending to a level below that suggested by consumer preferences and technology, i.e., below the first best allocation rule determined in section 3 . The economic rationale for restraining spending on public goods provision can be seen from the following equation which is also derived in appendix A.3:

$$
-u_{h}=\left(\frac{1+\eta}{\eta}-\frac{g+\widetilde{x}}{h}\right) u_{c}
$$

It shows that there exists a wedge between the marginal utility of (private) consumption and the disutility of labor that depends on the steady state interest payments $\widetilde{x} .^{8}$ The wedge thereby consists of two components: first, the monopoly power, which leads to the price mark-up $\frac{1+\eta}{\eta}$; second, the need to finance public expenditure and interest rate payments through distortionary taxation, which gives rise to the additional term in equation (28). Reducing public spending below its first best level, as suggested by equation (27), reduces the required labor tax rates and therefore helps reducing the overall wedge between the marginal utility of private consumption and the marginal utility of leisure. This suggests that in an economy with a higher stock of real government debt, i.e. a higher $\widetilde{x}$, the incentives to reduce public consumption below its first best level are stronger (ceteris paribus), simply because taxes are high already due to the high interest burden.

Interestingly, equation (28) shows that the steady state distortions could be entirely eliminated if the government had accumulated a sufficiently large amount of claims against the private sector, so that interest income allows to (1) offset the monopoly distortions via negative labor income tax rates and (2) to pay for (the first best level of) public goods provision.

\subsection{Numerical Solution and Model Calibration}

This section explains how one can determine locally approximate solutions for the optimal policies of the stochastic version of the model. Since there exists a continuum of deterministic steady states, one has to exogenously

\footnotetext{
${ }^{8}$ This is true whenever $\widetilde{x}$ is not too negative, i.e., whenever the government has not accumulated a too high level of claims against the private sector.
} 
choose one of the steady state dimensions. This is done by fixing the initial real value of outstanding government bonds $b_{-1}$ inherited from the past (which may be negative in case the government has accumulated claims against the private sector). ${ }^{9}$ One can then determine the steady state values for the remaining variables that solve the system of first order conditions of problem (17). ${ }^{10}$ Finally, one can determine first and second order accurate approximations to the optimal non-linear policy functions (18) and the state transition equations (40)-(44) using perturbation techniques. Details of the procedure are provided in appendix A.2.

For the numerical exercises the following preference specification is considered, which satisfies condition 1 and is consistent with balanced growth

$$
u\left(c_{t}, h_{t}, g_{t}\right)=\log \left(c_{t}\right)-\omega_{h} \frac{h_{t}^{1+\varphi}}{1+\varphi}+\omega_{g} \log \left(g_{t}\right)
$$

with $\omega_{h}>0, \omega_{g} \geq 0$ and the parameter $\varphi \geq 0$ denoting the inverse of the Frisch labor supply elasticity. The model is calibrated as summarized in table 1 below, following Adam and Billi (2008). The quarterly discount factor is chosen to match the average ex-post U.S. real interest rate, $3.5 \%$, during the period 1983:1-2002:4. The value for the elasticity of demand implies a gross mark-up equal to 1.2. The elasticity of labor effort is assumed to be one $(\varphi=1)$ and the values of $\omega_{h}$ and $\omega_{g}$ are chosen such that in the deterministic Ramsey steady state without government debt, agents work $20 \%$ of their time and it is optimal to spend $20 \%$ of total output on public goods. Appendix A.4 provides details on how the parameters have to be chosen to achieve this. The price stickiness parameter is selected such that the log-linearized version of the Phillips curve (12) is consistent with the estimates of Sbordone (2002), as in Schmitt-Grohé and Uribe (2004). The quarterly standard deviation of the technology shocks is $0.6 \%$ and the shocks have a quarterly persistence equal to $\rho_{z}=0.95$.

\footnotetext{
${ }^{9}$ One also needs to set the nominal interest rate that has been promised on the initial outstanding debt level. Since only $b_{-1} R_{-1}$ matters for the economic outcomes, one can set without loss of generality $R_{-1}=\beta^{-1}$.

${ }^{10}$ This assumes that the maximum tax revenue that can be raised according to the model's Laffer curve is sufficient to pay for the interest payments the assumed outstanding debt level, see the discussion in the next section.
} 


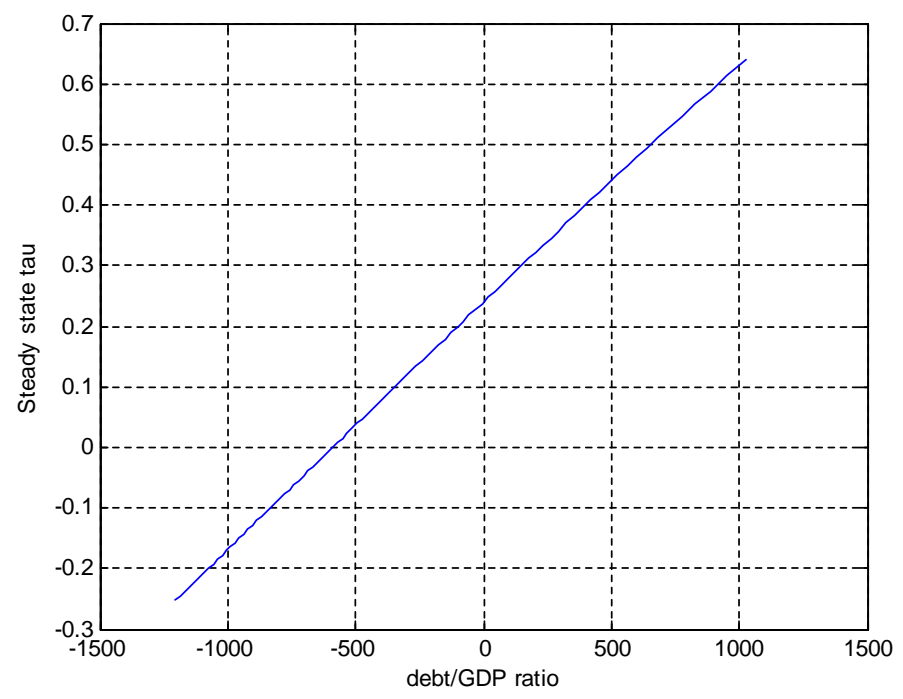

Figure 2: Steady State Tax Rates

\begin{tabular}{|l|l|}
\hline Parameter Definition & Assigned Value \\
\hline quarterly discount factor & $\beta=0.9913$ \\
price elasticity of demand & $\eta=-6$ \\
degree of price stickiness & $\theta=17.5$ \\
1/elasticity of labor supply & $\varphi=1$ \\
utility weight on labor effort & $\omega_{h}=19.792$ \\
utility weight on public goods & $\omega_{g}=0.2656$ \\
technology shock process persistence & $\rho_{z}=0.95$ \\
quarterly s.d. technology shock innovation & $\sigma=0.6 \%$ \\
\hline
\end{tabular}

Table 1: Baseline Calibration

\section{Steady State Implications of Government Debt}

This section explores the quantitative implications of different government debt levels for the deterministic steady state outcomes and steady state welfare. While the qualitative implications have been discussed in section 4.1 , this section shows that government debt gives rise to quantitatively important steady state effects.

Using the calibration from the previous section, table 2 below reports the steady state outcomes for private consumption, hours worked, government consumption and taxes for alternative initial debt levels. The last column of 


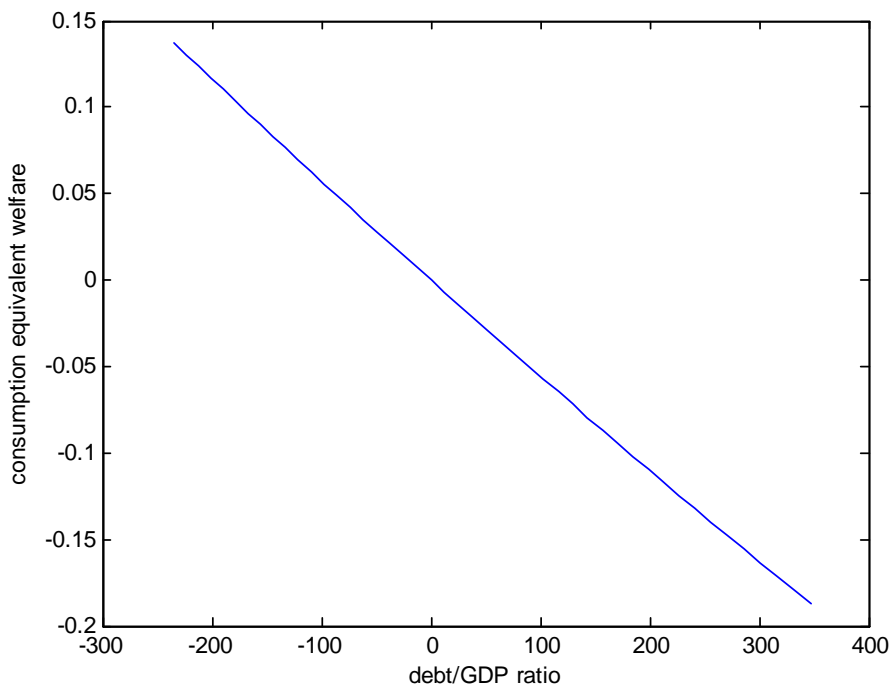

Figure 3: Steady State Welfare Implications of Government Debt

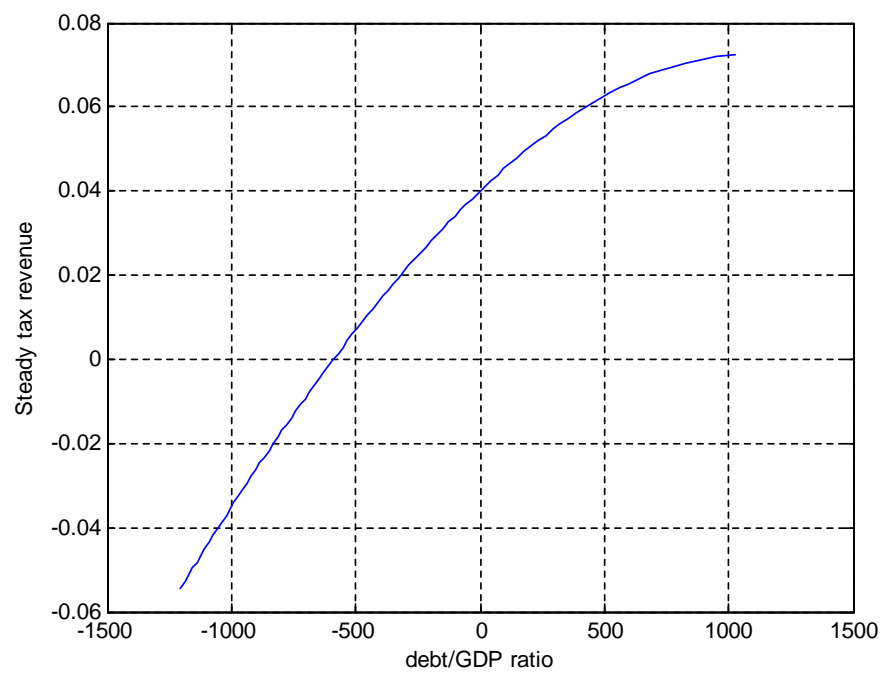

Figure 4: Laffer Curve 
the table lists the welfare equivalent consumption variation that is required each period to make agents in the zero debt steady state as well off as in the considered alternative debt scenarios. ${ }^{11}$ The outcomes for initial government debt levels equal to $100 \%$ and $200 \%$ of GDP, respectively, show that higher debt requires considerably higher income tax rates. These distort downward labor supply and thereby private consumption. Public consumption also decreases to avoid an even further increase in tax rates. The welfare implications of debt are large by any conventional standards and amount to $5.6 \%$ and $11 \%$ of consumption each period, respectively. This shows that there exist strong incentives for the Ramsey planner to default on the initial level of outstanding debt $R_{-1} b_{-1}$ at time $t=0$.

The table also reports the steady state outcome under a scenario with large negative government debt. The level of government claims against the private sector in this scenario is chosen so that the interest income earned by the government allows to pay for the first best level of public consumption and to offset the adverse labor supply effects of monopolistic competition via a negative income tax rate. Such a policy eliminates all steady state distortion in the economy, i.e., achieves the first best deterministic steady state allocation. This gives rise to a welfare increase of $70 \%$ of consumption each period. Monopoly power by firms and the requirement to raise government revenue trough distortionary income taxes thus give rise to large distortions in the economy, even in a setting where government debt is zero.

Overall, the effects of different steady state debt/GDP ratios on the allocations and tax rates are surprisingly linear. Figure 2 provides as an example for this outcome and depicts the optimal steady state tax rate as a function of the steady state debt/GDP ratio. The linearity emerges even though the model features an important non-linearity resulting from the Laffer curve. Figure 4 shows the steady state tax revenue as a function of the debt/GDP ratio (which figure 2 shows to be close to linearly related to the tax rate). At some point, tax revenue ceases to increase with the tax rate, implying that there exists a maximum sustainable deterministic steady state debt/GDP ratio. For the baseline calibration this level lies just above $1000 \%$ of GDP. Despite the existence of a Laffer curve, optimal taxes increase only about linearly with the debt/GDP ratio because government consumption optimally falls (approximately linearly) as the debt/GDP ratio increases.

\footnotetext{
${ }^{11}$ Let $\left(c_{Z}, h_{Z}, g_{Z}\right)$ denote the allocation in the zero debt steady state and $\left(c_{A}, h_{A}, g_{A}\right)$ the allocation in some alternative steady state. The table reports the percent increase in consumption $v$ making the zero debt steady state welfare-equivalent to the alternative steady state, i.e.,

$$
\log \left(c_{Z} *(1+v)\right)-\omega_{h} \frac{h_{Z}^{1+\varphi}}{1+\varphi}+\omega_{g} \log \left(g_{Z}\right)=\log \left(c_{A}\right)-\omega_{h} \frac{h_{A}^{1+\varphi}}{1+\varphi}+\omega_{g} \log \left(g_{A}\right)
$$
}




\begin{tabular}{|c|c|c|c|c|c|}
\hline & $\begin{array}{l}\text { priv. } \\
\text { cons. } \\
(c)\end{array}$ & $\begin{array}{l}\text { hours } \\
(h)\end{array}$ & $\begin{array}{l}\text { gov. } \\
\text { cons. } \\
(g)\end{array}$ & $\begin{array}{l}\text { taxes } \\
(\tau)\end{array}$ & $\begin{array}{l}\text { welfare equiv. } \\
\text { cons. variation }\end{array}$ \\
\hline Zero debt & 0.16 & 0.2 & 0.04 & $24 \%$ & $0.00 \%$ \\
\hline $\begin{array}{l}\text { 100\% debt/GDP } \\
\text { Change wrt zero debt }\end{array}$ & $\begin{array}{l}0.1558 \\
-2.61 \%\end{array}$ & $\begin{array}{l}0.1944 \\
-2.78 \%\end{array}$ & $\begin{array}{l}0.0386 \\
-3.47 \%\end{array}$ & $\begin{array}{c}28.0 \% \\
+16.8 \%\end{array}$ & $-5.58 \%$ \\
\hline $\begin{array}{l}\mathbf{2 0 0 \%} \text { debt/GDP } \\
\text { Change wrt zero debt }\end{array}$ & $\begin{array}{l}0.1516 \\
-5.25 \%\end{array}$ & $\begin{array}{l}0.1888 \\
-5.62 \%\end{array}$ & $\begin{array}{l}0.0372 \\
-7.02 \%\end{array}$ & $\begin{array}{l}32.0 \% \\
+33.3 \%\end{array}$ & $-11.0 \%$ \\
\hline $\begin{array}{l}\text { First best steady state } \\
-1076 \% \text { debt/GDP } \\
\text { Change wrt zero debt }\end{array}$ & $\begin{array}{c}0.2 \\
+25 \%\end{array}$ & $\begin{array}{c}0.2530 \\
+26.5 \%\end{array}$ & $\begin{array}{c}0.0530 \\
+32.5 \%\end{array}$ & $\begin{array}{l}-20 \% \\
\text { n.a. }\end{array}$ & $+70.6 \%$ \\
\hline
\end{tabular}

Table 2: Steady State Effects of Government Debt

The same approximate linearity holds true for the consumption equivalent welfare losses, which are shown in figure 3 . The convexity of the utility function implies, however, that the utility gains from consumption increases are somewhat smaller than the utility gains from consumption losses. The relationship between the debt/GDP ratio and steady state utility is thus convex, with increasing convexity at high debt/GDP ratios.

\section{Stabilization Policy and Budget Risks from Gov- ernment Debt}

This section studies the optimal monetary and fiscal policy response following a technology disturbance and shows how the optimal stabilization policy depends critically on the initial level of government debt. Specifically, under the optimal monetary and fiscal policy the government budget is exposed to larger risks from technology shocks, the larger is the outstanding level of government debt. Since first order accurate approximations to the optimal stabilization policies abstract from such risk considerations, first order approximations miss an important aspect of the truly optimal stabilization policy and wrongly predict debt to evolve like a random walk. 

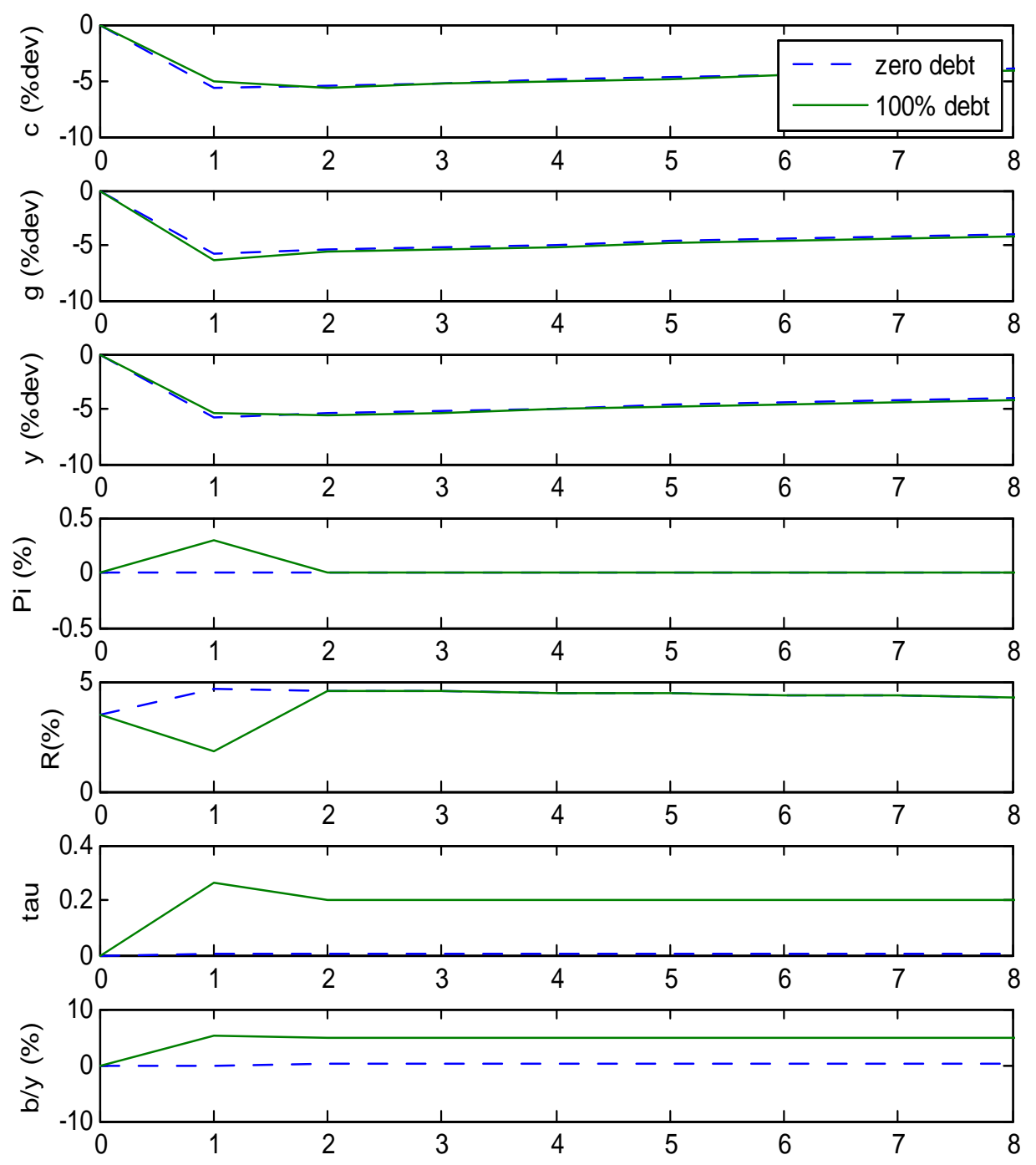

Figure 5: Impulse Response to a Negative Technology Shock (-3 std. dev.) 
Figure 5 illustrates that the level of government debt has important implications for the conduct of stabilization policy and for the evolution of government debt. The figure reports the dynamics implied by optimal policy around two alternative deterministic Ramsey steady states, one where the initial level of government debt level is zero and one where it equals $100 \%$ of GDP. Figure 5 depicts the first-order accurate impulse responses to a large negative technology shock. ${ }^{12}$ The shock size equals 3 unconditional standard deviations and implies that technology temporarily drops by about $5.7 \%$, thereafter slowly reverts to steady state. ${ }^{13}$

Under both debt scenarios, output, private and public consumption all drop by about the same amount as technology. ${ }^{14}$ Notable differences across the two scenarios emerge, however, when considering the optimal responses of inflation, nominal interest rates, taxes, and government debt.

When government debt is zero, there is no response of inflation, taxes or debt whatsoever. The reasons is that it is optimal to offset the reduction in tax revenue resulting from the negative technology shock by a corresponding reduction in government spending. This feature is a result of the assumed homotheticity of the utility function with respect to private and public consumption. It implies that in the absence of outstanding government debt, technology shocks do not give rise to uncertainty about future debt and taxes (up to first order accuracy). ${ }^{15}$ Technology shocks thus do not give rise to government 'budget risks' under the optimal stabilization policy.

The situation differs notably when government debt is positive. With positive debt levels, it is suboptimal to offset the drop in tax revenue following an adverse technology shocks entirely by a corresponding reduction in government spending. This is so because large part of the steady state tax revenue is used to pay interest on debt, so that an enormous government spending reduction would be required to balance the budget. This is suboptimal because the marginal utility of government consumption is very high since the steady state level of government spending is low at high debt levels, see the discussion in section 5 . While government spending falls more on impact when debt is high, the reduction is still insufficient to balance the budget. The government is thus forced to issue additional debt and to increase taxes to finance it. As a result, the debt level and the tax rate move permanently higher. This is an example of Barro's (1979) tax smoothing result, but emerging here in a setting with endogenous spending decisions, endogenous interest rates and following a technology disturbance. With a

\footnotetext{
${ }^{12}$ The second order effects are discussed in the next section.

${ }^{13}$ The assumed shock process implies that the economy spends less that $0.13 \%$ of the quarters in states with such or worse technology levels.

${ }^{14}$ The response is slightly more muted because the negative wealth effect of technology shocks implies that labor supply expands somewhat.

${ }^{15}$ This continues to be true when looking at second order accurate impulse responses in the next section.
} 
positive amount of government debt, technology shocks thus give risk to government 'budget risks' under the optimal stabilization policy, i.e., future debt and tax paths are uncertain and depend on the shock realizations.

Interestingly, when government debt is positive, it also becomes optimal to lower nominal interest rates on impact rather than increasing them, as would be optimal in the absence of government debt. This reduces real interest rates and implies a less severe collapse in output and consumption than otherwise in the first period. It also generates some small amount of inflation, which helps to reduce the real value of maturing government debt. Yet, as is known from the work of Schmitt-Grohé and Uribe (2004), it is suboptimal in the presence of even small amounts of nominal rigidities to bring about large price level changes, i.e., to use nominal bonds as a state contingent source of taxation. This finding shows up here in the form of rather small movements of inflation following a fairly large sized shock.

The first order accurate impulse response dynamics depicted in figure 5 show that the larger the amount of outstanding government debt, the larger are the 'budget risks' associated with technology shocks. Therefore, although up to first order accuracy, the government debt/GDP ratio evolves locally like a random walk, the fact that budget risk increases with the debt level should provide incentives to reduce government debt over time in the presence of shocks. ${ }^{16}$ This issue is investigated in the next section, which analyzes the second order accurate optimal equilibrium dynamics.

\section{Optimal Debt Dynamics}

This section evaluates to what extent the 'budget risk' associated with outstanding government debt documented in the previous section provides incentives to reduce government debt over time. To capture the optimal policy implications arising from budget risk considerations, this section considers a second order accurate approximation to optimal policy and the implied debt/GDP dynamics. ${ }^{17}$

As before, consideration is restricted to a local analysis around some pre-specified deterministic Ramsey steady state. The analysis thus ignores the incentives for debt reduction arising from global constraints such as borrowing constraints. As shown in Aiyagari et al. (2002), such global constraints can provide additional incentives for debt reduction. The point here is to show that potentially important incentives for debt reduction exist even when restricting consideration to a local analysis.

Figure 6 depicts the optimal drift in the debt/GDP ratio as a function of assumed steady state debt/GDP ratio. Specifically, the figure reports the constant in the state transition law for bonds emerging from a second order

\footnotetext{
${ }^{16}$ In the absence of shocks, it is optimal to hold debt constant over time.

${ }^{17}$ The solution approach is explained in appendix A.2.
} 


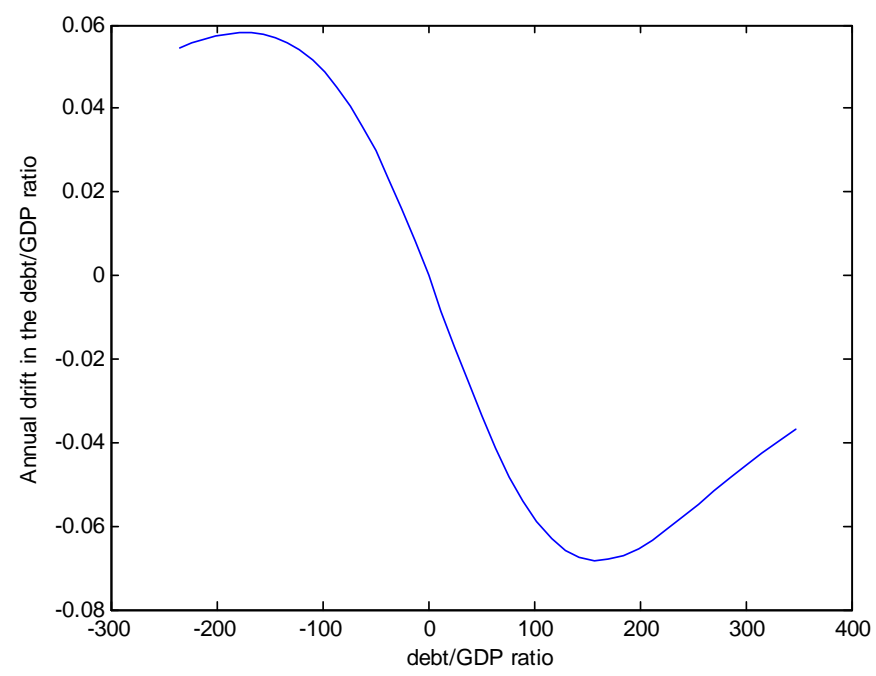

Figure 6: The Optimal Speed of Debt Reduction (baseline shock parameterization)

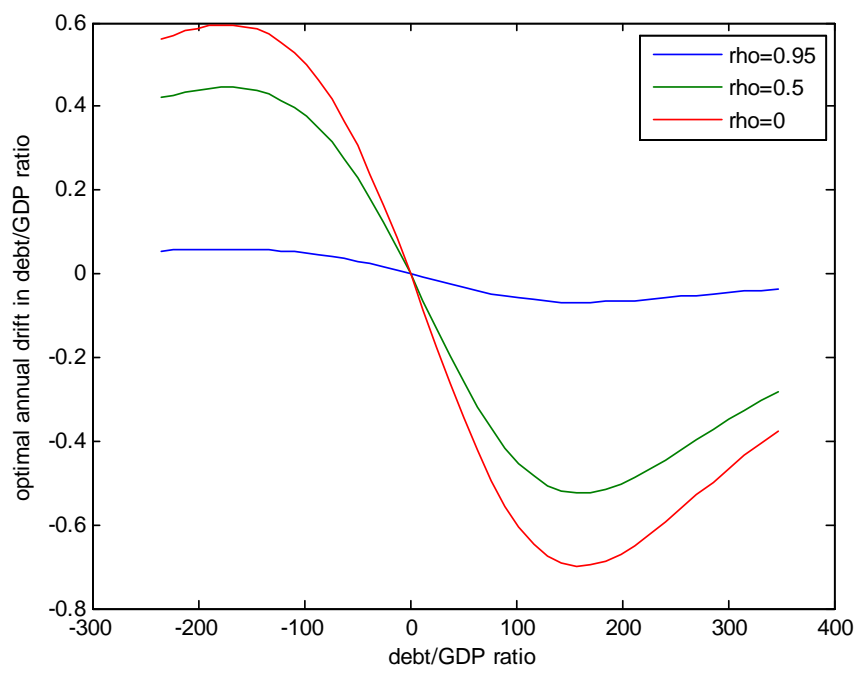

Figure 7: The Optimal Speed of Debt Reduction: Alternative Shock Processes 

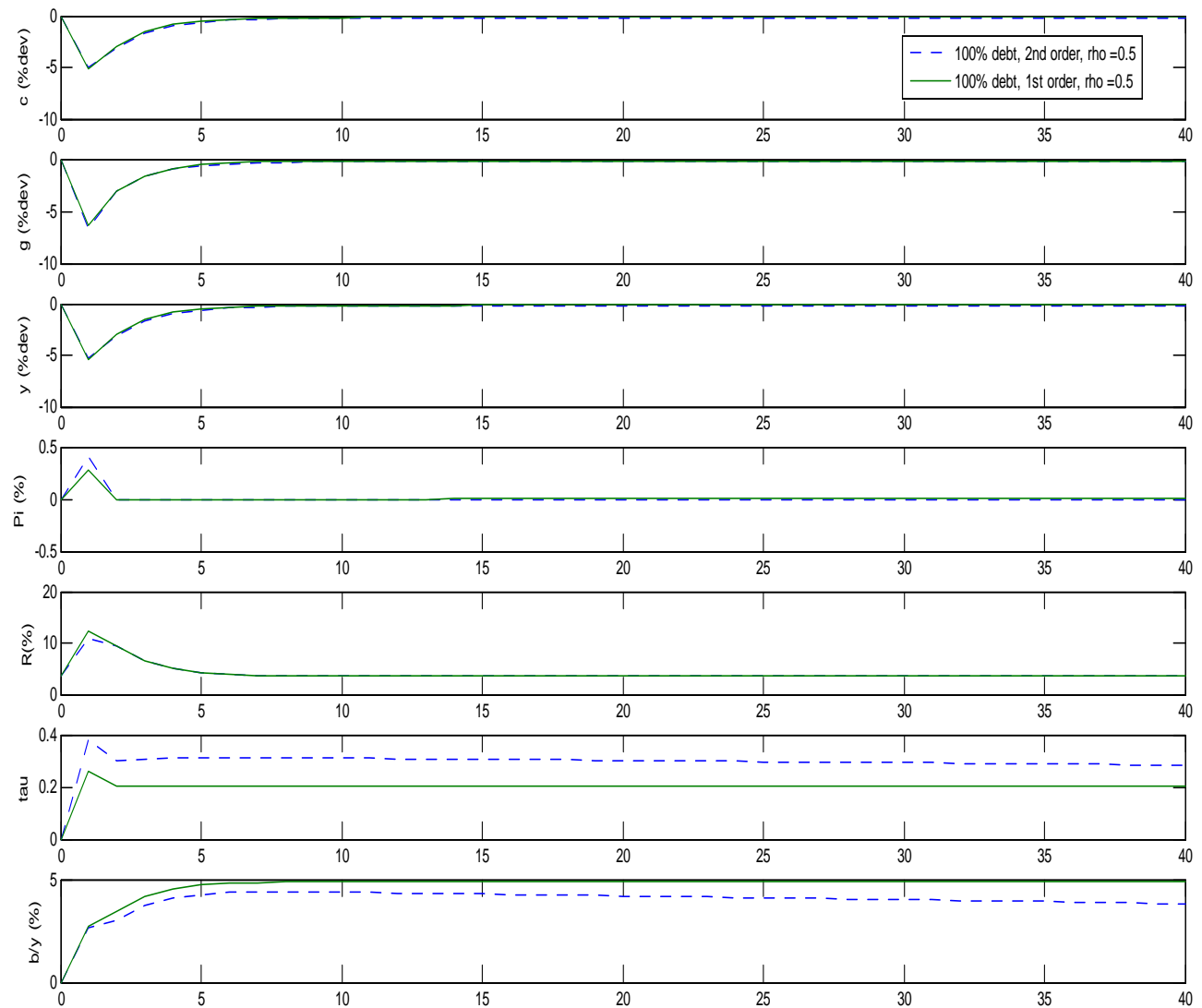

Figure 8: Comparison of First and Second Order Accuarate Impulse Responses 
accurate approximate solution to optimal monetary and fiscal policy using the baseline parameterization, and scales this constant by the GDP level. It shows that there is a tendency for debt to fall whenever it is positive and to increase whenever it is negative. This suggests that over time debt optimally converges to zero. ${ }^{18}$

Quantitatively, the drift term turns out not to be very large in the baseline parameterization. This finding is fairly robust to many parameter changes, except when the unpredictable components of technology shocks increase. To illustrate this finding, figure 7 depicts the optimal debt drift under less persistent technology shock processes. The standard deviation of the innovation to the technology process is thereby adjusted so as to keep the overall unconditional standard deviation of technology shocks unchanged when compared to the baseline specification. As the figure shows, it may then be optimal to reduce the debt to GDP ratio by as much as $0.6 \%$ per year. This shows that second order effects can easily become quantitatively significant.

Figure 8 illustrates this fact by comparing the first and second order accurate impulse responses to a negative technology shock. ${ }^{19}$ It shows that important differences emerge between a first and second order accurate approximation of the optimal response of taxes and government debt. Especially, the optimal evolution of government debt deviates significantly from random walk behavior.

Interestingly, the optimal speed of the debt drift in figures 6 and 7 is non-monotone in the initial debt/GDP ratio. Specifically, as the debt/GDP ratio increases, the optimal speed of debt reduction first rises but then falls. It is actually not surprising, that this relationship can be non-monotone. While budget risk increases with the debt level, as shown in the previous section, the cost of repaying debt may equally rise, due to the existence of a Laffer curve. The cost of repayment may thereby rise faster or slower than the benefits of repayment, so that the relationship between the debt/GDP ratio and the optimal speed of debt repayment can be non-monotone.

Figures 6 and 7 also show that for sufficiently negative debt levels the government actually reduces the speed at which it decumulates its claims against the private sector. While budget risk increases as debt becomes more negative, the utility consequences of any given amount of risk also decrease. This is so because utility is flat locally with respect to tax changes at the point where the government holds just enough claims allowing it to implement the first best equilibrium in the absence of shocks. As a result,

\footnotetext{
${ }^{18}$ This differs from the results in Aiyagari et al. (2002) where debt converged to a large negative value. Unlike in Aiyagari et al, the present setup does not allow for lump sum rebates of government revenue.

${ }^{19}$ The assumed shock persistence is $\rho_{z}=0.5$. As before, the standard deviation of the technology shock innovation is adjusted so as to keep the unconditional standard deviation of technology shocks unchanged compared to the baseline parameterization.
} 
the optimal speed of debt increase may be non-monotonically related to the level of claims that the government has accumulated against the private sector.

\section{Optimal Debt Dynamics with Exogenous Spend- ing}

Most of the public finance literature treats the process for government spending as exogenous. ${ }^{20}$ Moreover, in some of these models, exogenous government spending shocks are the only source of randomness, so that budget risk is independent of the government debt level. ${ }^{21}$ This section shows that debtdependent 'budget risk' continues to provide incentives for debt reduction if one allows for technology shocks, even in a setting with an exogenously fixed spending path. Indeed, the incentives for debt reduction can become even stronger. The analysis in this section is also of interest, because it is informative about the optimal speed of debt reduction in a setting where institutional restrictions prevent the government from adjusting public spending in response to aggregate technology shocks.

Figure 9 illustrates the effects of exogenously fixing government spending on the optimal debt drift and compares it to the drift emerging with endogenous spending decisions. ${ }^{22}$ To make the comparison meaningful, the figure reports for each given deterministic steady state value of the debt/GDP ratio the drift coefficients that emerge from a second order approximation of the two models, assuming that in the model with exogenous spending the level of public consumption is exogenously fixed at the deterministic steady state value arising in the model with endogenous spending decisions. The figure thus isolates for each given level of the debt/GDP ratio the effects of not being able to adjust the government spending level following technology shocks.

The figure shows that the unavailability of the government spending margin provides additional incentives for debt reduction whenever the government has positive amounts of debt outstanding. This suggest that inertia or exogeneity of government spending plans amplifies the optimal speed of debt reduction compared to the situation studied in the paper thus far. Also, unlike in the case with endogenous spending, the zero debt steady state ceases to be an absorbing state when spending is exogenous. ${ }^{23}$ With zero debt and exogenous spending, technology shocks require an adjustment

\footnotetext{
${ }^{20}$ See, for example, Schmitt-Grohé and Uribe (2004).

${ }^{21}$ See, for example, the classic papers by Barro (1979) and Aiyagari et al. (2002).

${ }^{22}$ The figure assumes $\rho_{z}=0.5$. As before, the standard deviation of the technology shock innovation is adjusted to keep the unconditional standard deviation of technology shocks unchanged compared to the baseline parameterization.

${ }^{23} \mathrm{With}$ endogenous spending this is true up to second order of accuracy.
} 


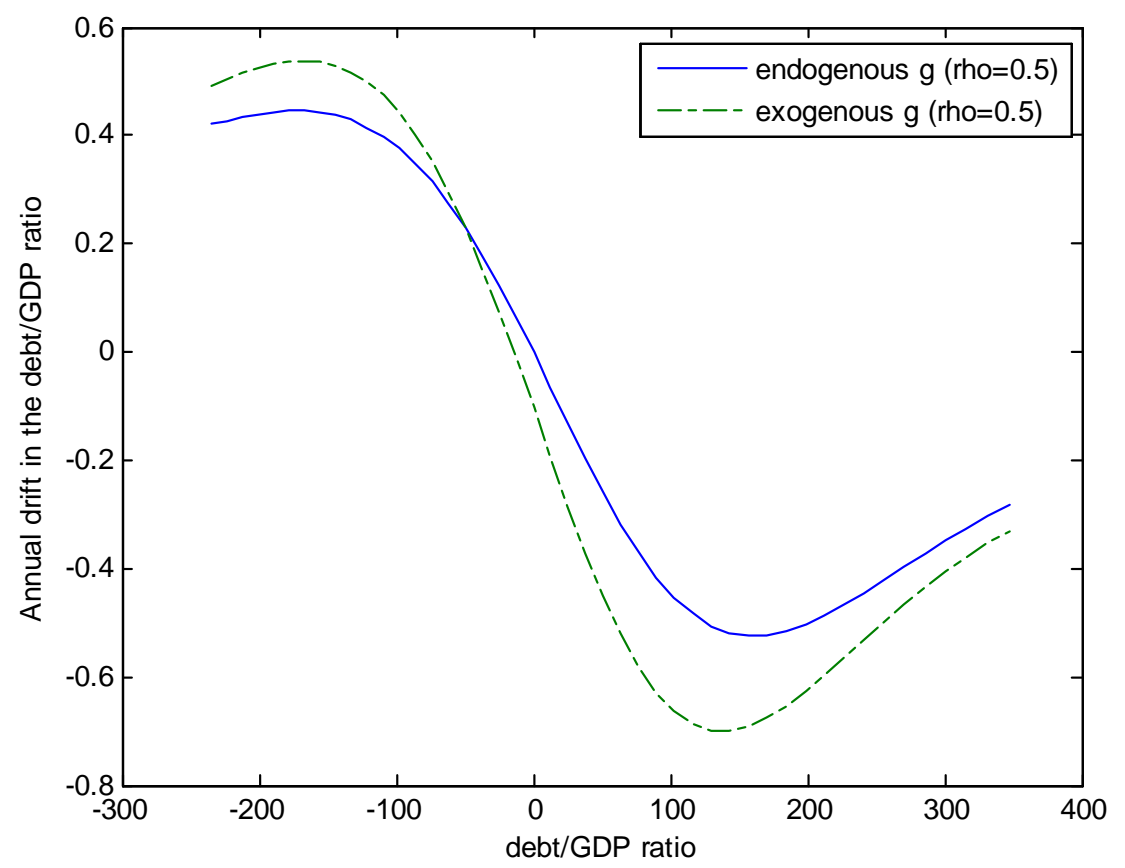

Figure 9: Optimal Speed of Debt Reduction: Exogenous vs. Endogenous Gov. Spending

of taxes and debt, i.e., give rise to budget risk. As figure 9 shows, this provides incentives for the government to accumulate claims against the private sector.

\section{Conclusions}

This paper shows that the recent increase in government debt has important implications for the optimal conduct of monetary and fiscal policy. Higher government debt requires lowering the average level of public spending and exposes fiscal budgets to increased risks following technology shocks or more generally - fluctuations in the tax base. These budget risk considerations can provide quantitatively important incentives to reduce government debt over time, but the optimal speed of debt reduction is not necessarily monotone in the level of accumulated government debt. As a result, optimal debt dynamics deviate in important ways from random walk behavior. The results in this paper suggest that debt optimally converges to zero over time and that the optimal speed of debt reduction tends to increase if governments cannot adjust their spending plans following fluctuations in the tax 
base.

For a number of reasons, the present paper may have significantly understated the optimal speed of debt reduction. First, global inequality constraints, such as the borrowing limit implied by the Laffer curve, may provide additional incentives for debt reduction. Taking this constraint into account requires solving the model fully non-linearly, along the lines of Adam and Billi (2006). This appears to be an interesting task for future research. Second, the present paper focused exclusively on technology shocks. Other shocks, e.g., shocks to agents' discount factors give rise to additional sources of budget risk, as they move the real interest rates at which the government can refinance its outstanding debt. Exploring the quantitative relevance of such alternative disturbances for the optimal speed of debt reduction appears to be an equally interesting task for future research. 


\section{A Appendix}

\section{A.1 FOCs and Solution Strategy}

The first order conditions of problem (17) with respect to the decision variables $\left(c_{t}, h_{t}, \Pi_{t}, R_{t}, \tau_{t}, g_{t}, b_{t}\right)$ are

$$
\begin{aligned}
& c_{t}: 0=u_{c, t}+\left(\gamma_{t}^{1}-\mu_{t}^{1}\right) u_{c c, t}\left(\Pi_{t}-1\right) \Pi_{t}-\gamma_{t}^{1} \frac{u_{c c, t} z_{t}}{\theta} h_{t}\left(1+\eta+\frac{u_{h, t}}{u_{c, t}\left(1-\tau_{t}\right)} \frac{\eta}{z_{t}}\right) \\
&-\gamma_{t}^{1} \frac{u_{c, t} z_{t}}{\theta} h_{t}\left(\frac{-u_{c c, t}}{\left(u_{c, t}\right)^{2}} \frac{u_{h, t}}{\left(1-\tau_{t}\right)} \frac{\eta}{z_{t}}\right) \\
&+\gamma_{t}^{2} \frac{u_{c c, t}}{R_{t}}-\mu_{t}^{2} \frac{u_{c c, t}}{\Pi_{t}}-\gamma_{t}^{3}+\gamma_{t}^{4}\left(\frac{\tau_{t}}{1-\tau_{t}} u_{h, t} h_{t} \frac{u_{c c, t}}{\left(u_{c, t}\right)^{2}}\right) \\
& h_{t}: 0=u_{h, t}-\gamma_{t}^{1} \frac{u_{c, t} z_{t}}{\theta}\left(\left(1+\eta+\frac{u_{h, t}}{u_{c, t}\left(1-\tau_{t}\right)} \frac{\eta}{z_{t}}\right)+h_{t} \frac{u_{h h, t}}{u_{c, t}\left(1-\tau_{t}\right)} \frac{\eta}{z_{t}}\right) \\
&+\gamma_{t}^{3} z_{t}-\gamma_{t}^{4} \frac{\tau_{t}}{1-\tau_{t}} \frac{1}{u_{c, t}}\left(u_{h h, t} h_{t}+u_{h, t}\right) \\
& \Pi_{t}: 0=\left(\gamma_{t}^{1}-\mu_{t}^{1}\right) u_{c, t}\left(2 \Pi_{t}-1\right)+\mu_{t}^{2} \frac{u_{c, t}}{\left(\Pi_{t}\right)^{2}}-\gamma_{t}^{3} \theta\left(\Pi_{t}-1\right)+\gamma_{t}^{4} \frac{R_{t-1} b_{t-1}}{\left(\Pi_{t}\right)^{2}} \\
& R_{t}: 0=-\gamma_{t}^{2} \frac{u_{c, t}}{\left(R_{t}\right)^{2}}-\beta b_{t} E_{t} \frac{\gamma_{t+1}^{4}}{\Pi_{t+1}} \\
& \tau_{t}: 0=-\gamma_{t}^{1} \frac{u_{c, t} z_{t}}{\theta} h_{t}\left(\frac{u_{h, t}}{u_{c, t}} \frac{\eta}{z_{t}} \frac{1}{\left(1-\tau_{t}\right)^{2}}\right)-\gamma_{t}^{4}\left(\frac{1}{\left(1-\tau_{t}\right)^{2}} \frac{u_{h, t}}{u_{c, t}} h_{t}\right) \\
& g_{t}: 0=u_{g, t}-\gamma_{t}^{3}-\gamma_{t}^{4} \\
& b_{t}: 0=\gamma_{t}^{4}-\beta E_{t} \gamma_{t+1}^{4} \frac{R_{t}}{\Pi_{t+1}}
\end{aligned}
$$

The derivatives with respect to the first three Lagrange multipliers are given by:

$$
\begin{aligned}
u_{c, t}\left(\Pi_{t}-1\right) \Pi_{t}-\frac{u_{c, t} z_{t}}{\theta} h_{t}\left(1+\eta+\frac{u_{h, t}}{u_{c, t}\left(1-\tau_{t}\right)} \frac{\eta}{z_{t}}\right) & \\
-\beta E_{t} u_{c, t+1}\left(\Pi_{t+1}-1\right) \Pi_{t+1} & =0 \\
\frac{u_{c, t}}{R_{t}}-\beta E_{t} \frac{u_{c, t+1}}{\Pi_{t+1}} & =0 \\
z_{t} h_{t}-c_{t}-\frac{\theta}{2}\left(\Pi_{t}-1\right)^{2}-g_{t} & =0
\end{aligned}
$$


We can then define 5 state variables and the corresponding 5 transition equations:

$$
\begin{aligned}
z_{t+1} & =\mu_{z}+\rho_{z} z_{t}+\alpha_{z, 0} \varepsilon_{z, t+1} \\
\mu_{t+1}^{1} & =\gamma_{t}^{1} \\
\mu_{t+1}^{2} & =\gamma_{t}^{2} \\
b_{t} & =\frac{\tau_{t}}{1-\tau_{t}} \frac{u_{h, t}}{u_{c, t}} h_{t}+g_{t}+\frac{R_{t-1}}{\Pi_{t}} b_{t-1} \\
R_{t} & =R_{t}
\end{aligned}
$$

where the forth equation is the derivative of the Lagrangian (17) with respect to the last multiplier and the $\mu_{t}^{i}$ denote the lagged Lagrange multipliers associated with the forward looking constraints in (17). In the last equation, $R_{t}$ denotes both the future state variable and the current decision variable. As we show below, optimal policies are going to be a function of these state variables.

The state transition equations (40)-(44), the FOCs (30)-(36), and the implementability constraints (37)-(39) form a system of 5 state transition equations and 10 additional equations of the form

$$
E_{t} f\left(x_{t+1}, y_{t+1}, x_{t}, y_{t}\right)=0
$$

which is of the form analyzed in Gomme and Klein (2010). As argued in Gomme and Klein, a nonlinear solution to this system of nonlinear expectational difference equations is given by nonlinear decision functions of the form

$$
y_{t}=g\left(x_{t}, \sigma\right)
$$

where $y_{t}=\left(c_{t}, h_{t}, \Pi_{t}, R_{t}, \tau_{t}, g_{t}, \gamma_{t}^{1}, \gamma_{t}^{2}, \gamma_{t}^{3}, \gamma_{t}^{4}\right)$ denote the decision variables (note that this list does not contain $b_{t}$ ) and where $x_{t}=\left(z_{t}, \mu_{t}^{1}, \mu_{t}^{2}, b_{t-1}, R_{t-1}\right.$ ) denotes the state vector. The parameter $\sigma$ thereby denotes the standard deviation of the technology shock innovation. The nonlinear state transition is thereby described by equations (40)-(44).

\section{A.2 Local Approximation of Optimal Dynamics}

Let $(\bar{x}, \bar{y})$ denote a deterministic steady state of the nonlinear equation system (45) solving

$$
f(\bar{x}, \bar{y}, \bar{x}, \bar{y})=0
$$

A second order approximation of the non-linear solution (46) around this steady state is given by a decision function

$$
\widetilde{y}_{t}=k_{y}+F \widetilde{x}_{t}+\frac{1}{2}\left(I_{5} \otimes \widetilde{x}_{t}^{\prime}\right) E \widetilde{x}_{t}
$$


and a state transition function

$$
\widetilde{x}_{t+1}=k_{x}+P \widetilde{x}_{t}+\frac{1}{2}\left(I_{10} \otimes \widetilde{x}_{t}^{\prime}\right) G \widetilde{x}_{t}+\sigma \varepsilon_{t+1}
$$

where the tilde indicates that a variable is expressed in terms of deviations from its steady state. The approximation is taken with respect to the expansion variable $\sigma$ around $\sigma=0$ and the values for $\left(k_{y}, F, E\right)$ and $\left(k_{x}, P, G\right)$ can be computed using the code provided by Gomme and Klein (2010). The first order accurate dynamics of the model can be obtained by the same equations when setting $k_{y}, k_{x}, E, G$ all equal to zero.

\section{A.3 Ramsey Steady State}

To simplify matters we start by eliminating taxes and the government budget constraint from the Lagrangian (17). Note that the FOCs (6) and (7) imply

$$
\frac{-u_{h, t}}{u_{c, t}}=\left(1-\tau_{t}\right) w_{t}=w_{t}-\tau_{t} w_{t}
$$

and from steady state version of the government budget (26) we have

$$
\tau_{t} w_{t}=\frac{g_{t}+\widetilde{x}}{h_{t}}
$$

Substituting the latter equation into the former gives the following expression for the real wage

$$
w_{t}=-\frac{u_{h, t}}{u_{c, t}}+\frac{g_{t}+\widetilde{x}}{h_{t}}
$$

which allows expressing the Phillips curve without reference to taxes. The simplified constant debt version of the Lagrangian (17) is then

$$
\begin{aligned}
& \max _{\left\{c_{t}, h_{t}, \Pi_{t}, R_{t} \geq 1, g_{t}\right\}_{t=0}^{\infty}} \min _{\left\{\gamma_{t}^{1}, \gamma_{t}^{2}, \gamma_{t}^{3}\right\}} \sum_{t=0}^{\infty} \beta^{t} u\left(c_{t}, h_{t}, g_{t}\right) \\
& +\beta^{t} \gamma_{t}^{1}\left(\begin{array}{c}
u_{c, t}\left(\Pi_{t}-1\right) \Pi_{t}-\frac{u_{c, t} z_{t} h_{t}}{\theta}\left(1+\eta+\eta\left(\frac{u_{h, t}}{u_{c, t}}-\frac{g_{t}+\widetilde{x}}{h_{t}}\right)\right) \\
-\beta\left[u_{c, t+1}\left(\Pi_{t+1}-1\right) \Pi_{t+1}\right]
\end{array}\right) \\
& +\beta^{t} \gamma_{t}^{2}\left(\frac{u_{c, t}}{R_{t}}-\beta\left[\frac{u_{c, t+1}}{\Pi_{t+1}}\right]\right) \\
& +\beta^{t} \gamma_{t}^{3}\left(h_{t}-c_{t}-\frac{\theta}{2}\left(\Pi_{t}-1\right)^{2}-g_{t}\right)
\end{aligned}
$$


The FOCs consist of the three constraints and

$$
\begin{aligned}
& c_{t}: u_{c, t}+\left(\gamma_{t}^{1}-\gamma_{t-1}^{1}\right) u_{c c, t}\left(\Pi_{t}-1\right) \Pi_{t}-\gamma_{t}^{1} \frac{u_{c c, t} z_{t} h_{t}}{\theta}\left[1+\eta-\eta \frac{g_{t}+\widetilde{x}}{h_{t}}\right] \\
& +\gamma_{t}^{2} \frac{u_{c c, t}}{R_{t}}-\gamma_{t-1}^{2} \frac{u_{c c, t}}{\Pi_{t}}-\gamma_{t}^{3}=0 \\
& h_{t}: u_{h, t}-\gamma_{t}^{1} \frac{u_{c, t}}{\theta}\left(1+\eta+\eta\left(\frac{u_{h, t}}{u_{c, t}}-\frac{g_{t}+\widetilde{x}}{h_{t}}\right)+h_{t} \eta\left(\frac{u_{h h, t}}{u_{c, t}}+\frac{g_{t}+\widetilde{x}}{\left(h_{t}\right)^{2}}\right)\right)+\gamma_{t}^{3}=0 \\
& \Pi_{t}:\left(\gamma_{t}^{1}-\gamma_{t-1}^{1}\right)\left(2 \Pi_{t}-1\right)+\gamma_{t-1}^{2}\left(\frac{-u_{c, t}}{\left(\Pi_{t}\right)^{2}}\right)-\gamma_{t}^{3} \theta\left(\Pi_{t}-1\right)=0 \\
& R_{t}: \gamma_{t}^{2} \frac{-u_{c, t}}{\left(R_{t}\right)^{2}}=0 \\
& g_{t}: u_{g, t}+\gamma_{t}^{1} \frac{u_{c, t}}{\theta} \eta-\gamma_{t}^{3}=0
\end{aligned}
$$

We now impose steady state conditions by dropping time subscripts. From (51)

$$
\gamma^{2}=0
$$

so that (50) gives

$$
\Pi=1
$$

and from (13) one obtains

$$
R=\frac{1}{\beta}
$$

Using these results and imposing them on the steady state version of the derivative of (47) with respect to $\gamma_{t}^{1}$ one obtains

$$
\frac{-u_{h}}{u_{c}}=\frac{1+\eta}{\eta}-\frac{g+\widetilde{x}}{h}
$$

which is equation (28) in the main text. Since $u_{h}<0$ and $u_{c}>0$ the previous equation implies

$$
1+\eta-\eta \frac{g+\widetilde{x}}{h}<0
$$

In the steady state equations (48), (49) and (52) simplify to

$$
\begin{array}{r}
u_{c}-\gamma^{1} \frac{u_{c c} h}{\theta}\left[1+\eta-\eta \frac{g+\widetilde{x}}{h}\right]-\gamma^{3}=0 \\
u_{h}-\gamma^{1} \frac{\eta}{\theta}\left(u_{h h} h+u_{c} \frac{g+\widetilde{x}}{h}\right)+\gamma^{3}=0 \\
u_{g}+\gamma^{1} \frac{\eta}{\theta} u_{c}-\gamma^{3}=0
\end{array}
$$


where $\gamma^{3}>0$ denotes the marginal utility of relaxing the resource constraint. The previous FOCs indicate the alternative possible uses of additional resources, namely private consumption (equation (55)), leisure (equation (56)) and public consumption (equation (57)). Since public consumption is only one of three possible uses of resources, it must be the case that $\gamma^{3} \geq u_{g}$ in the optimum. Equation (57) therefore implies that $\gamma^{1} \geq 0$. Combining equations (55) and (57) to eliminate $\gamma^{3}$ then gives

$$
u_{c}=\frac{u_{g}+\gamma^{1} \frac{u_{c c} h}{\theta}\left[1+\eta-\eta \frac{g+\widetilde{x}}{h}\right]}{\left(1-\gamma^{1} \frac{\eta}{\theta}\right)}
$$

From $\gamma^{1} \geq 0$ and (54) then follows that

$$
\begin{aligned}
u_{c} & =\frac{u_{g}+\gamma^{1} \frac{u_{c c} h}{\theta}\left[1+\eta-\eta \frac{g+\widetilde{x}}{h}\right]}{\left(1-\gamma^{1} \frac{\eta}{\theta}\right)} \\
& \leq u_{g}+\gamma^{1} \frac{u_{c c} h}{\theta}\left[1+\eta-\eta \frac{g+\widetilde{x}}{h}\right] \\
& \leq u_{g}
\end{aligned}
$$

and since $u_{c}>-u_{h}$, we have $u_{g}>-u_{h}$, as claimed in the main text.

\section{A.4 Utility Parameters and Ramsey Steady State}

Here we show how the utility parameters $\omega_{h}$ and $\omega_{g}$ are determined by the Ramsey steady state values. Let variables without subscripts denote their steady state values and consider the Ramsey steady state with constant debt from appendix A.3. Since $\Pi=1$ the Phillips curve constraint in (47) implies

$$
1+\eta-\eta\left(\omega_{h} h^{\varphi} c-\frac{g+\widetilde{x}}{h}\right)=0
$$

which delivers

$$
\omega_{h}=\frac{\left(\frac{1+\eta}{\eta}-\frac{g+\widetilde{x}}{h}\right)}{h^{\varphi} c}
$$

and allows to determine the steady state values of $u_{h}$ and $u_{h h}$. Adding up equations (55) and (56) then delivers

$$
\gamma_{1}=\frac{u_{c}+u_{h}}{\left(\frac{\eta}{\theta}\left(u_{h h} h+u_{c} \frac{g+\widetilde{x}}{h}\right)+\frac{u_{c c} h}{\theta}\left[1+\eta-\eta \frac{g+\widetilde{x}}{h}\right]\right)}
$$

and (56) gives

$$
\gamma^{3}=-u_{h}+\gamma^{1} \frac{\eta}{\theta}\left(u_{h h} h+u_{c} \frac{g+\widetilde{x}}{h}\right)
$$

It then follows from $(57)$

$$
\omega_{g}=g\left(\gamma^{3}-\gamma^{1} \frac{\eta}{\theta} u_{c}\right)
$$




\section{References}

Adam, K., And R. Billi (2008): "Monetary Conservatism and Fiscal Policy," Journal of Monetary Economics, 55, 1376-1388.

(2009): "Distortionary Fiscal Policy and Monetary Policy Goals," University of Mannheim Mimeo.

Adam, K., And R. M. Billi (2006): "Optimal Monetary Policy under Commitment with a Zero Bound on Nominal Interest Rates," Journal of Money Credit and Banking, 38(7), 1877-1905.

Aiyagari, S. R., A. Marcet, T. J. Sargent, and J. Seppälä (2002): "Optimal Taxation Without State-Contingent Debt," Journal of Political Economy, 110(6), 1220-1254.

Barro, R. J. (1979): "On the Determination of Public Debt," Journal of Political Economy, 87 (5), 940-971.

Chari, V., L. J. Christiano, and P. J. Kehoe (1991): "Optimal Fiscal and Monetary Policy: Some Recent Results," Journal of Money Credit and Banking, 23, 519-539.

Díaz-Giménez, J., G. Giovannetti, R. Marimon, and P. Teles (2008): "Nominal Debt as a Burden on Monetary Policy," Review of Economic Dynamics, 11, 493-514.

Gomme, P., and P. Klein (2010): "Second-Order Approximation of Dynamic Models Without the Use of Tensors," University of Western Ontario Mimeo.

Leeper, E. M. (1991): "Equilibria under Active and Passive Monetary and Fiscal Policies," Journal of Monetary Economics, 27, 129-147.

Leith, C., I. Moldovan, and R. Rossi (2009): "Monetary and Fiscal Policy under Deep Habits," University of Glasgow, Department of Economic Working Paper 32.

Leith, C., And S. Wren-Lewis (2007): "Fiscal Sustainability in a New Keynesian Model," University of Oxford, Economics Series Working Papers 310 .

Rotemberg, J. J. (1982): "Sticky Prices in the United States," Journal of Political Economy, 90, 1187-1211.

Sbordone, A. (2002): "Prices and Unit Labor Costs: A New Test of Price Stickiness," Journal of Monetary Economics, 49, 265-292. 
Schmitt-Grohé, S., and M. Uribe (2004): "Optimal Fiscal and Monetary Policy under Sticky Prices," Journal of Economic Theory, 114(2), 198-230.

Woodford, M. (1998): "Doing Without Money: Controlling Inflation in a Post-Monetary World," Review of Economic Dynamics, 1, 173-209. 